importance of having the ophthalmic service linked up with other departments such as the laboratory, radiological and other departments of a general hospital. The second section of the report sets forth the principles of organization and procedure which are believed to be essential for a satisfactory out-patient service in our speciality. Consultation facilities have already been mentioned; with regard to organization and personnel, ward service and outpatient service go hand in hand; unified service is to be aimed at ; every member of the staff should have some duties and privileges in the out-patient department, and, after a proper period of probation, some ward and operating duties and privileges; the chief of clinic should be the senior assistant surgeon in the operating room, he should be in direct charge of the clinic work under the direction of the surgeon. Each new patient should be seen by the surgeon or by the chief of the clinic before a diagnosis is made or treatment instituted; the entire staff should be assigned definite hours for attendance in the out-patient department, the chief of the clinic to be present during the whole clinic session of the day on which he is on duty; clinic conferences should be held every week, and junior men should be encouraged to shew cases and make reports; lastly, the ophthalmologist should be relieved, as far as possible, of all duties not connected with the professional care of the patients. Under space, arrangement, equipment and facilities, a very complete armamentarium is devised ; in regard to procedure, it is strongly laid down that the number of patients admitted on any day should be no more than can be adequately dealt with by the staff. Much of this report is ideal ; but in this country the question of the expense is prohibitive. Most hospitals are so badly off that the governing bodies would refuse to sanction the appointment of paid refraction assistants; while, without rebuilding the whole out-patient department, it would be sometimes impossible to provide room for an adequate service such as is outlined. English ophthalmologists must, we fear, continue to carry on as best they can with the facilities provided, such as they are; it is extremely difficult to organize proper teaching when the surgeon is singlehanded and has to treat the patients without assistance, or with only inadequate assistance. Yet we feel that this report is one that should be read and studied by all connected with the management or care of an out-patient department.

\title{
Mackenzie's Diseases of the Eye; Author's Copy with holograph notes
}

Peculiar interest is attached to copies of any works which have been the author's own personal property, and particularly is such the case when the book in question is a famous one. No one could doubt the value of such a book as Harvey's great work on the 
circulation; if the first edition with the author's marginal notes were to appear on the market, it would be priceless. We think that ophthalmologists throughout the world will agree with us in the supposition that, in our own speciality, the famous book by William Mackenzie, of Glasgow, on diseases of the eye, is of such a character. As Dr. Freeland Fergus has pointed out in his article on the author in the British Journal of Ophthalmology, Vol. 1, p. 145, Mackenzie's was one of the last of the great textbooks in our subject that appeared before the dawn of modern scientific ophthalmology, and with that by Sir William Lawrence, by far the most complete. The date of its publication was within the antiphlogistic age, a time when inflammation was combated by most drastic methods; how our forefathers found room for the enormous numbers of leeches that were applied round an inflamed eye has always been a mystery: calomel and antimony were in the ascendant, and it can have been no light ordeal for anyone to go through the orthodox mode of treatment for such a condition as iritis in those good old days; such a patient could compare himself with perfect truth to those of whom it is said that they had passed through great tribulation. Through the generosity of Dr. A. Maitland Ramsay, the Bowman Library has recently been enriched by the gift of the first edition of Mackenzie's book in two volumes, interleaved, and dated 1830. What makes this gift so extraordinarily interesting is the fact that on almost every page the author has written notes referring to cases similar to the ones under discussion, which have occurred in his practice and in current literature; even the covers have been utilized in this way, while in some places extra slips of paper have been carefully pasted in. The book is practically as it left the great author's consulting-room table, and after a lapse of more than 90 years pieces of contemporary blotting paper can be found between its leaves. References to cases abound on nearly every page; in places, tags of Latin and of Greek are inserted: the most interesting of these occurs in reference to the case of the facial wound sustained by the Duke of Guise at the siege of Calais, reported by Ambroise Paré; this wound was caused by a fragment of an English lance, which Paré was able to remove with a pair of farrier's pincers, and the scar resulting therefrom gave the nickname of "le balafre" to the Duke, which persisted throughout his life. Mackenzie notes as follows: "This description will naturally recall to the classical reader, the fatal wound of Pandarus in the Iliad,". and then follow the four lines of the Greek, with liber 5,290 at the foot.

The author seems to have utilized any and every piece of paper which came in his way, for on the back of one slip occurs the following fragment of a letter: "Sir, I request your company 
on Wednesday the 30th current at 2 p.m. to attend the funeral of - my brother, yours faithfully."

Space does not allow us to give any lengthy extracts from the notes which are written in the rather crabbed, though perfectly legible handwriting of the author; suffice it to say, that those who are interested can easily find the volumes in question by consulting the library card index. Let us hope that those who take the trouble to examine these unique historical treasures will echo the words of the writer of Ecclesiasticus: "Let us now praise famous men and the fathers that begat us," and be grateful to the President of the Ophthalmological Society of the United Kingdom for his most interesting and valuable gift.

\section{INTERNATIONAL CONGRESS OF OPHTHALMOLOGY (I925)-Notice of Postponement}

The Committee of British Ophthalmologists appointed to organize an International Congress in 1925 finds, with regret, that it is unable to do so in accordance with the conditions under which the British invitation was accepted by the Washington Ophthalmological Congress in 1922. It will be remembered that at Washington it was decided that the next Congress should be strictly International and that German should be one of the official languages. The Committee has since been informed that the Société Française d'Ophtalmologie, the Société d'Ophtalmologie de Paris and the Société Belge d'Ophtalmologie have passed resolutions to the effect that they feel themselves unable to participate in a Congress if Germans are invited. The Committee is of opinion that to proceed with the Congress in these circumstances would tend to perpetuate a schism in the ranks of Ophthalmology and militate permanently against the progress of the science which all desire to promote. The Committee has, therefore, reluctantly decided to postpone the Congress.

\section{OXFORD OPHTHALMOLOGICAL CONGRESS, I923}

THE fourteenth annual meeting of the Oxford Ophthalmological Congress was held at Oxford on July 4, 5, 6, and 7. Members met at dinner on the evening of Wednesday, July 4 , in the Hall of Keble College. The proceedings took place in the Department of Human Anatomy of the University Museum, which had been once more placed at the disposal of the Congress by 